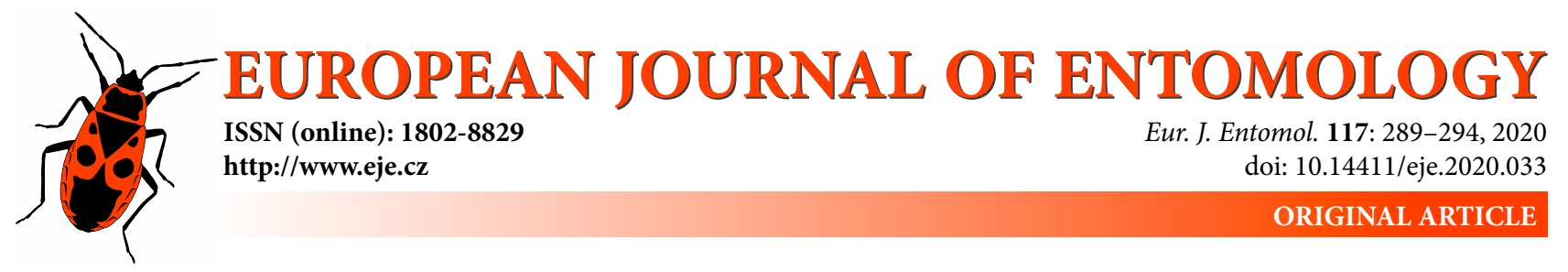

\title{
Soil salinity determines the diversity of snail-killing flies (Diptera: Sciomyzidae) in brackish marshes
}

\author{
FRANK VAN DE MEUTTER ${ }^{1}$, JonAs MORTELMANS ${ }^{2}$ and RALF GYSELINGS ${ }^{1}$ \\ ${ }^{1}$ Research Institute for Nature and Forest (INBO), Herman Teirlinckgebouw, Havenlaan 88 bus 73, 1000 Brussel, Belgium; \\ e-mails: Frank.vandemeutter@inbo.be, ralf.gyselings@inbo.be \\ ${ }^{2}$ Flanders Marine Institute (VLIZ), Wandelaarkaai 7, 8400 Oostende, Belgium; e-mail: jonasmortelmans@gmail.com
}

Key words. Diptera, Sciomyzidae, snail-killing flies, insect diversity, soil salinity, brackish marshes, Atlantic brackish meadows, Belgium

\begin{abstract}
Brackish marshes resulting from embankments are a rare habitat in Europe and for which there is little knowledge of the entomofauna. There is an urgent need to document the insect diversity and its unique properties in the light of ongoing habitat losses. The current study focuses on snail-killing flies in the remaining Belgian brackish marshes, in particular the role of soil salinity in determining their diversity and how it compares with that in freshwater marshes. Snail-killing fly communities in brackish marshland were relatively species poor and clearly different from those in freshwater, yet species richness and abundance increased with decreasing soil salinity. We recorded no habitat-specific species, but Tetanocera arrogans was more abundant in brackish marshes. Malaise traps proved to be a successful and repeatable method of sampling sciomyzid communities, the species composition of which was strongly site-specific. We conclude that extant Belgian brackish marshes have poor to moderately rich snail-killing fly communities that lack unique species. Richness and abundance, however, increased as soil salinity decreased.
\end{abstract}

\section{INTRODUCTION}

Saltmarsh and brackish marsh occur globally along sheltered coasts and in estuaries and have been altered or degraded by humans for many centuries, especially in Northern Europe. For example, $40 \%$ of the current territory of the Netherlands was previously saltmarsh (Airoldi \& Beck, 2007; Gedan et al., 2008; Janssen et al., 2017). Main causes of habitat losses are land reclamation for agriculture, coastal defence, expansion of coastal settlements and development of port facilities (Wolters et al., 2005; Airoldi \& Beck, 2007; Bakker, 2014). Saltmarshes and brackish marshes are highly valued natural areas both for their large store of natural capital (e.g. high levels of stored carbon) and their large, productive and unique biodiversity (Millennium Ecosystem Assessment, 2005; Wieski et al., 2010; Pennings, 2012). In Western-Europe, an inland subtype of Atlantic saltmarshes that are no longer tidal as they are permanently cut off from the sea are common. These marshes are situated next to the coastline or in estuaries and are a result of embankments of tidal saltmarsh and brackish marsh. To distinguish them from other inland brackish marshes we call these marshes polder brackish marshes (PBM). Continued inflow of saline seepage maintains their saline nature. It is suggested that PBM differ biologically from their tidal counterpart, however, knowledge is scarce especially of the biodiversity and specificity of the invertebrate community (Zwaenepoel et al., 2002).

All Belgian PBM are situated within the Flemish Polder region. The total area is estimated to be not more than 150 ha (Feys et al., 2015) and though locally it has increased due to nature restoration (Bakker et al., 2009) at other places ongoing land reclamation and agricultural land improvement have greatly reduced its effect. Importantly, the area of original, high-quality, extensively managed PBM continues to decrease due to land conversion or adverse activities on their peripheries (Feys et al., 2015) which could reduce their biodiversity and especially the survival of rare habitat-specific species. Conservation and management of current PBM is strongly focused on plants and birds. The breeding densities of several wader species may reach high levels in this habitat (Beintema \& Timmerman, 1976). Knowledge on the occurrence and requirements of other elements of the fauna is very limited (but see Van de Meutter et al., 2016a) and the inclusion of invertebrates in conservation assessments and management of PBM is virtually non-existent. As such, there are currently barely any incentives for invertebrate oriented management.

Marsh flies or snail-killing flies (Sciomyzidae) are a rather small dipterous family with approximately 148 species in Europe and 76 in Belgium. Taxonomy and ecology of snail-killing flies is well-resolved and they are poten- 
tially good indicator species of marshlands (Carey et al., 2017). They are comparatively well studied in terms of their potential as bio-control agents of disease-carrying or agriculturally important snails and slugs (Murphy et al., 2012). Sciomyzid larvae with one exception are all obligate natural enemies of Mollusca, being either predators or parasitoids (Keiper et al., 2002; Vala \& Gbedjissi, 2011). The majority of their hosts are aquatic or semi-aquatic, which is why the diversity and abundance of snail-killing flies is highest in marshlands. Diversity of snail-killing flies in very saline environments is low (Neff \& Berg, 1962; Szadziewski, 1983; Knutson \& Vala, 2011). Polder brackish marshes, however, generally tend to become desalinized over time and range from freshwater to brackish marsh depending on the inflow of brackish seepage. Thus, they may offer a favourable and unique habitat for some invertebrate groups, including snail-killing flies, but as yet there is no data to validate this assumption.

The current study is part of a larger project to record the biodiversity in the scarce and threatened PBM habitat. Here we aim to study the snail-killing fly communities in Belgian PBMs and compare them with those in freshwater marshes. Fly communities were sampled using standard flight interception traps in the four major remaining PBMs in Belgium and in some inland freshwater marshes. The main questions to be answered are: (1) What is the composition of snail-killing fly communities in PBMs? (2) Are PBM snail-killing fly communities consistently different from those in freshwater communities? (3) Are there any unique species present in PBMs? (4) How is the snail-killing fly community in PBM affected by soil salinity?

\section{MATERIAL AND METHODS}

\section{Study sites, sampling methods and processing}

Four of the largest and best preserved PBMs in Belgium were selected for this study: Putten Weiden (10 ha, Kieldrecht, henceforth "PUWE"), "t Pompje (9 ha Oudenburg, "OUD"), Uitkerkse polder (39 ha in separated fragments near Blankenberge, "UIT") and Monnikenwerve ( 8 ha, Lissewege, "MON"). The first site is located in the polder along the Scheldt estuary near Antwerp, the other three are situated in the polder region near the North Sea coast (Fig. 1, coordinates in Table 1). Together these marshes make up nearly half of the extant area of PBMs in Belgium.

Freshwater marshes selected for this study (for coordinates see Table 1) were near the lake of Virelles (Virelles, "VIRL"), the Dunbergbroek (Holsbeek, "DUNB"), Demerbroeken (Scherpenheuvel-Zichem, "DEMB") and Papenbroek (Kaggevinne, "PAEP"). Each of these sites consists of a mixture of open marshy grasslands up to several hectares in extent with ditches, ponds or lakes and some shrub or woodland. Of all the sites studied, the brackish Putten Weiden and the freshwater Demerbroeken sites are prone to regular flooding in winter. Grazing is more common at brackish sites (3/4 brackish sites versus $1 / 4$ freshwater sites), but sampling locations were located within ungrazed or lightly grazed (tall herbaceous vegetation present) areas.

Snail-killing fly communities were sampled using Malaise traps (black fabric, British museum type). The number of Malaise traps deployed at the different sites is indicated in Table 1 and ranged between 1 and 4. Malaise traps installed at the same site were at least $50 \mathrm{~m}$ apart. Traps were installed along transverse vegetation structures such as reed belts and low shrubs or

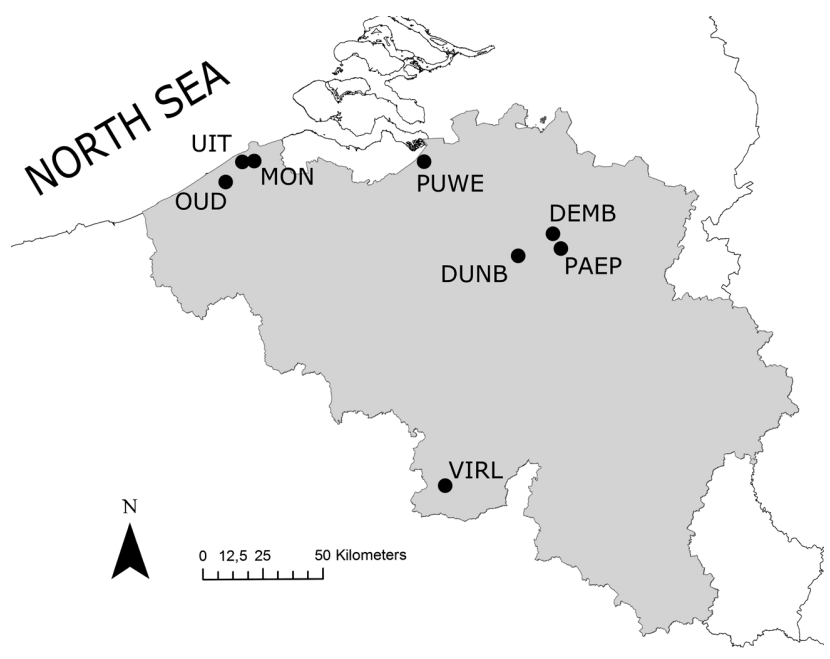

Fig. 1. Map of Belgium (in grey) showing the locations sampled. For abbreviations see Table 1.

in longitudinal depressions. Malaise traps placed in PBMs were located within larger stands of typically brackish marsh vegetation. The collection bottle filled with $70 \%$ alcohol always pointed to the south. Traps were fenced off with a single strand of barbwire to fend off grazing cattle. Vegetation within and around the traps was regularly pushed or cut down during sampling to guarantee an open entrance to the traps. Malaise traps were deployed between the end of March and end of October and samples were collected on average biweekly. The marshes were sampled in 2006 (VIRL), 2010 (DEMB), 2012 (DUNB, PAEP, MON, PUWE, OUD) and 2013 (UIT). All samples were sorted to family level on white trays and all Sciomyzidae identified to species level using Rozkošný (1984), Vala (1989) and Rozkošný (1991).

At the brackish marsh sites soil salinity was measured in the vegetation surrounding the traps using rhizons (Rhizosphere $\mathrm{C}$ ). Rhizons consist of $8.5 \mathrm{~cm}$ hydrophilic, porous polymer tubes that can be drilled into the soil. We exposed the tube at soil depths of -3 to $-11.5 \mathrm{~cm}$ below ground level (see also Van de Meutter et al., 2016a). Negative suction pressure is created by vacuum tubes to collect soil moisture. An electrical conductivity probe (WTW (C) Multiline P3) was used to measure conductivity of the extracted fluid. Water conductivity was then recalculated to chlorinity using an equation derived from previous field studies on Belgian brackish marshlands (Van de Meutter et al., 2016b). Rhizon measurements were recorded at a site in the same year as the flies were sampled. At each site, pore water was collected with rhizons at 6 locations, stratified over 2 common land cover types (open muddy soil and vegetation dominated by Juncus gerardii (Loisel.). Measurements were recorded at the end of April, begin-

Table 1. Marsh type, number of Malaise traps, year sampled and geographic coordinates of the sites sampled.

\begin{tabular}{lccccc}
\hline Site & $\begin{array}{c}\text { Fresh (F) / } \\
\text { Brackish (B) }\end{array}$ & \# traps & Year & Lat & Long \\
\hline VIRL & F & 4 & 2006 & 50.07192 & 4.33478 \\
DEMB & F & 1 & 2010 & 51.01384 & 4.98380 \\
MON & B & 2 & 2012 & 51.28940 & 3.20440 \\
OUD & B & 2 & 2012 & 51.20930 & 3.03510 \\
DUNB & F & 1 & 2012 & 50.93262 & 4.77543 \\
PAEP & F & 1 & 2012 & 50.95821 & 5.02873 \\
PUWE & B & 2 & 2012 & 51.28870 & 4.21960 \\
UIT & B & 3 & 2013 & 51.28580 & 3.13330 \\
\hline
\end{tabular}


ning of June and first half of August. For each site, we calculated the average of the soil salinities recorded on all dates and locations as an indicator of general soil salinity.

The regional ecology, status and distribution of sciomyzidae in Belgium used to interpret the results is based on a database $\left(\mathrm{N}_{\text {records }}=4320\right)$ being developed by JM, which currently incorporates all the material in the collection of the Royal Belgian Institute of Natural Sciences and other material recently collected in Belgium by the authors.

\section{Data analysis}

Prior to the analyses, the raw data on species recorded on particular days were transformed to year sums for each species per trap. To compare the abundance of sciomyzid flies in freshwater and brackish marshes a Kruskall-Wallis test was used to test siteaveraged total snail-killing fly abundance per trap. Because richness and abundance are correlated, we also constructed rarefied species accumulation curves using pooled trap samples per site in order to analyse differences in species richness. The rarefied species number for each site at the lowest recorded trap abundance $(\mathrm{N}=54, \mathrm{PAEP})$ was used to compare species richness of freshwater and brackish marshes using a Kruskall-Wallis test.

To explore community differences at the trap and site level, we applied Nonmetric Dimensional Scaling (NMDS) using the function metaMDS in the Vegan package. To test for differences in community composition between brackish and freshwater marshland communities, we used the Analysis of similarities (ANOSIM) with 999 permutations. ANOSIM analyses were done for site level using data summed over all traps. Because of differences in sample sizes among sites, we used the Chao dissimilarity index. Species occurring in less than three Malaise traps and for which less than 10 specimens were caught in this study were not included in both the NMDS and ANOSIM.

To test if typical indicator species of snail-killing flies exist for brackish marshland, we used a slightly modified version of the Indicator species analysis (IndVal index) (Dufrêne \& Legendre, 1997) included in the Indicspecies package. The relation between soil salinity and species richness (both actual and rarefied) and abundance was calculated using Spearman rank correlation.

The NMDS (using the function metaMDS), ANOSIM and rarefaction were done within the Vegan package (Oksanen et al., 2018). The Indicator species analysis was done within the Indicspecies package (De Caceres \& Legendre, 2009). All analyses were carried out in RStudio (RStudio Team, 2016).

\section{RESULTS}

\section{Abundance and richness}

A total of 1742 specimens and 40 species of sciomyzid flies were caught by the Malaise traps (Table 2). On average 118 specimens and 11.6 species of snail-killing flies were recorded per trap. Species richness (or species density, Gotelli \& Colwell, 2001) tended to be lower in brackish marshes compared to freshwater marshes $(\mathrm{H}(1)=$ $3.073, \mathrm{p}=0.08)$, but abundance did not differ $(\mathrm{H}(1)=2.08$, $\mathrm{p}=0.15$ ). The rarefied species number (at $\mathrm{N}=54$ ) was significantly lower in brackish marshes than in freshwater marshes $(\mathrm{H}(2)=4.083, \mathrm{p}=0.043)$.

\section{Relation with soil salinity}

Soil salinity at the different PBM sites varied considerably and ranged from $12,000[\mathrm{Cl}-](\mathrm{mg} / \mathrm{l})$ at the Monnikenwerve site to $3,100[\mathrm{Cl}-](\mathrm{mg} / \mathrm{l})$ at Oudenburg (for more details, see Van de Meutter et al., 2016a). Soil salinity
Table 2. List of all the species caught in this study with the number caught in each type of marsh (brackish, freshwater) and the total number of each species. In the heading of each column the number of Malaise traps used in each type of marsh is in brackets.

\begin{tabular}{lccc}
\hline Species & \multicolumn{3}{c}{ Brackish Freshwater } \\
& $(\mathrm{N}=9)$ & $(\mathrm{N}=7)$ & \\
\hline Anticheta brevipennis (Zetterstedt, 1846) & 2 & 5 & 7 \\
Colobaea bifasciella (Fallen, 1820) & 2 & 34 & 36 \\
Colobaea distincta (Meigen, 1830) & 1 & 0 & 1 \\
Colobaea pectoralis (Zetterstedt, 1847) & 0 & 13 & 13 \\
Ditaeniella grisescens (Meigen, 1830) & 3 & 0 & 3 \\
Elgiva cucularia (Linnaeus, 1767) & 1 & 11 & 12 \\
Elgiva solicita (Harris, 1780) & 12 & 1 & 13 \\
Hydromya dorsalis (Fabricius, 1775) & 3 & 3 & 6 \\
Ilione albiseta (Scopoli, 1763) & 19 & 4 & 23 \\
Limnia paludicola Elberg, 1965 & 1 & 2 & 3 \\
Limnia unguicornis (Scopoli, 1763) & 25 & 28 & 53 \\
Pherbellia albocostata (Fallen, 1820) & 1 & 5 & 6 \\
Pherbellia cinerella (Fallen, 1820) & 4 & 0 & 4 \\
Pherbellia dorsata (Zetterstedt, 1846) & 4 & 7 & 11 \\
Pherbellia goberti (Pandelle, 1902) & 0 & 13 & 13 \\
Pherbellia griseola (Fallen, 1820) & 5 & 34 & 39 \\
Pherbellia nana (Fallen, 1820) & 5 & 0 & 5 \\
Pherbellia schoenherri (Fallen, 1826) & 0 & 33 & 33 \\
Pherbina coryleti (Scopoli, 1763) & 84 & 45 & 129 \\
Psacadina verbekei Rozkosny, 1975 & 0 & 9 & 9 \\
Psacadina zernyi Mayer, 1953 & 0 & 1 & 1 \\
Pteromicra angustipennis (Staeger, 1845) & 12 & 453 & 465 \\
Pteromicra glabricula (Fallen, 1820) & 0 & 1 & 1 \\
Pteromicra leucopeza (Meigen, 1838) & 2 & 2 & 4 \\
Renocera pallida (Fallen, 1820) & 0 & 108 & 108 \\
Sciomyza dryomyzina Zetterstedt, 1846 & 0 & 12 & 12 \\
Sciomyza simplex Fallen, 1820 & 43 & 93 & 136 \\
Sciomyza testacea Macquart, 1835 & 10 & 19 & 29 \\
Sepedon sphegea (Fabricius, 1775) & 4 & 1 & 5 \\
Sepedon spinipes (Scopoli, 1763) & 4 & 0 & 4 \\
Tetanocera arrogans Meigen, 1830 & 198 & 21 & 219 \\
Tetanocera elata (Fabricius, 1781) & 0 & 10 & 10 \\
Tetanocera ferruginea Fallen, 1820 & 120 & 66 & 186 \\
Tetanocera freyi Stackelberg, 1963 & 0 & 56 & 56 \\
Tetanocera fuscinervis (Zetterstedt, 1838) & 0 & 12 & 12 \\
Tetanocera hyalipennis Roser, 1840 & 0 & 15 & 15 \\
Teta montana Day, 1881 & 0 & 16 & 16 \\
Tera punctulata (Scopoli, 1763) & 0 & 4 & 4 \\
\hline
\end{tabular}

correlated negatively with species density ( rho $=-0.79, \mathrm{p}$ $=0.011$ ) and species richness based on rarefaction (rho $=$ $-0.82, p=0.007)$ and tended to correlate negatively with abundance ( $\mathrm{rho}=-0.62, \mathrm{p}=0.072$ ).

\section{Community similarity}

Stress levels for repeated runs of the NMDS were all $<12.2$ with values of $\sim 10$ considered to be suitable for reasonable interpretation (McCune \& Mefford, 2016). In the NMDS plot of the Malaise trap data from the same PBM they are situated close to each other, indicating they had similar sciomyzid communities (Fig. 2). In the NMDS plots of both freshwater and PBM communities, PBM communities clearly separate from freshwater marshland communities along the first axis (Fig. 3). The spatial configuration of the trap samples in the NMDS plot is very similar for analyses including all species $\left(\mathrm{N}_{\text {species }}=40\right)$ or only selected species $\left(\mathrm{N}_{\text {species }}=20\right)$, which indicates this is 


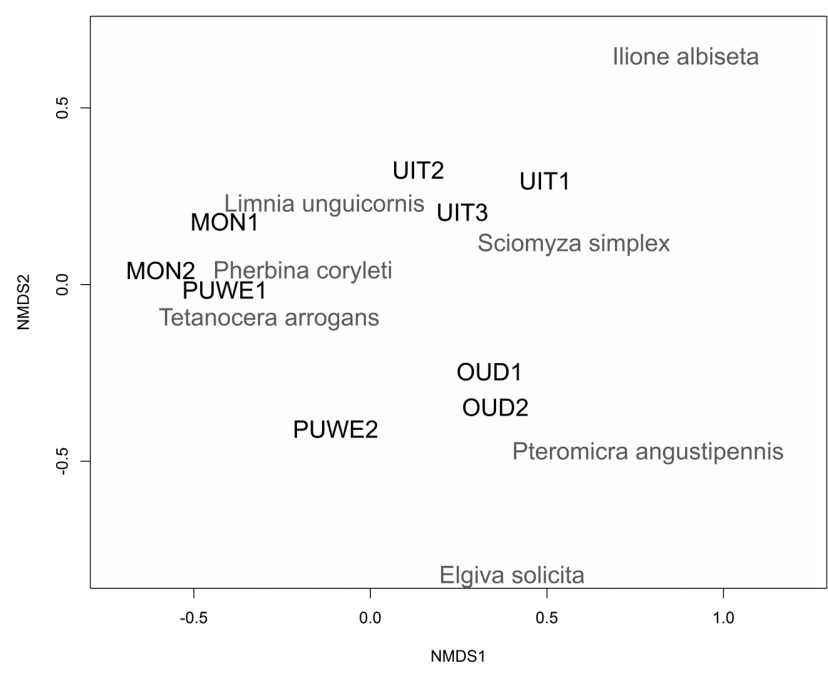

Fig. 2. NMDS plot of the snail-killing fly catches in brackish marshes. For site abbreviations: see Table 1. Each name on the plot represents a Malaise trap.

a stable pattern. The distinction between freshwater and PBM snail-killing fly communities is further confirmed by the results of the ANOSIM analysis $(\mathrm{R}=0.78, \mathrm{p}=0.041)$. Five species were found only in brackish marsh: Colobaea distincta (Meigen, 1830), Ditaeniella grisescens (Meigen, 1830), Pherbellia cinerella (Fallen, 1820), Pherbellia nana nana (Fallen, 1820) and Sepedon spinipes (Scopoli, 1763). All five species occurred in low numbers. The indicator species analysis revealed one species with a significant IndVal score related to brackish marsh: Tetanocera arrogans Meigen, 1830. This species was the second most common species sampled and $90.4 \%$ of them were recorded in brackish marsh.

\section{DISCUSSION}

Polder brackish marshes are a rare habitat in Belgium and Europe and there is little known about their entomofauna. There is an urgent need to document this diversity and its unique properties as their habitat, brackish marshes, is under threat. The current study focuses on snail-killing flies in the remaining Belgian PBMs and compares it with the situation in freshwater marshes. Polder brackish marshland snail-killing fly communities were relatively species poor compared to freshwater marsh communities, but more diverse than recorded in tidal brackish or saltmarsh communities (Mortelmans J. \& Van de Meutter F., pers. obs., Szadziewski, 1983). Species richness and abundance of snail-killing fly communities in PBM increased with decreasing salinity. Tetanocera arrogans is an indicator species of PBM, however it is a widespread and common species in Belgium. We conclude that currently Belgian PBMs support snail-killing fly communities intermediate between freshwater and tidal brackish or saltmarsh communities, with diversity and abundance increasing with decrease in soil salinity, but lack unique species.

Of the five species uniquely found in the brackish marshes in this study, only D. grisescens is associated exclusively with the Belgian polder ecoregion where the PBMs are

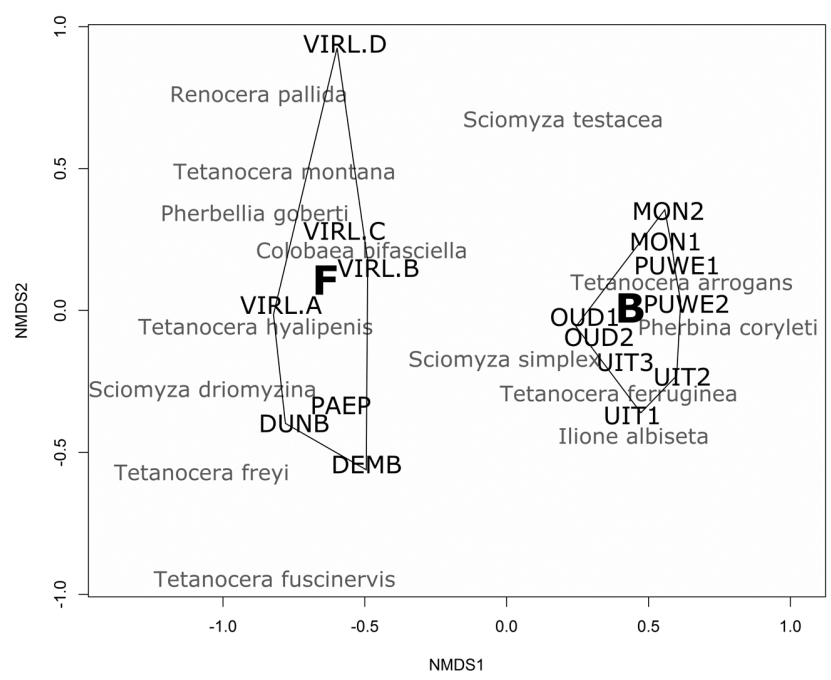

Fig. 3. NMDS plot of the snail-killing fly catches in freshwater and brackish marshes. For site abbreviations: see Table 1. Each name on the plot represents a Malaise trap. Envelopes were drawn for freshwater ( $F$ ) and brackish (B) sites with the letters indicating the centroids.

located. A coastal affinity of this species is also reported by Szadziewski (1983), however this is not an obligate feature of this species as there is one historical inland record for Belgium and elsewhere this species is reported from other ecoregions (e.g., Speight \& Knutson, 2012). The other four species, however, are not confined to PBMs within Belgium and are not unique species of brackish marsh. Their unique presence in PBMs may be a sampling effect. An indicator species identified by the Indval analyses, which was abundant in the brackish marshes sampled, was $T$. arrogans. This species is considered to be linked with terrestrial (Chapman et al., 2006) or semi-terrestrial habitats (Knutson \& Vala, 2011; Vala et al., 2012), where it lives as a parasitoid of Succineidae snails. In Belgium it is a widespread species, but in the absence of detailed information on the presence and abundance of potential hosts, it is unclear why it preferred brackish marsh in this study.

The strong negative effect of soil salinity on the richness and abundance of snail-killing flies is probably largely due to its detrimental effect on their molluscan larval hosts (e.g., Costil et al., 2001; Gérard et al., 2003). A similar rationale is used to explain the negative relationship between sciomyzid diversity and soil pH (Carey et al., 2017). We do not think that our results are significantly affected by other environmental parameters such as flooding frequency or grazing management (Williams et al., 2009). Flooding frequency was not different at brackish and freshwater sites. Grazing management was more common on brackish marshes, however in the absence of grazing the community composition or richness did not shift from typically brackish to freshwater or vice versa. Traps were installed so that the type of vegetation surrounding them was structurally similar at all sites, which may have alleviated differences due to management, or its effect was simply subordinate to that of salinity. The presence of Sciomyzidae in PBM is probably due to the spatially complex salinity gradients 
often found in such systems (Van de Meutter et al., 2016b), commonly resulting in a mosaic of freshwater and brackish conditions in such marshes. In addition, in Belgian PBMs soil has a high $\mathrm{pH}$ and relatively high levels of $\mathrm{Ca}^{2+}$, which is beneficial for molluscs and may favour a good number of sciomyzid species where salinity levels are low. Inventories of Belgian coastal saltmarshes and brackish marshes in the tidal Scheldt estuary reveal an extremely poor sciomyzid communities, which may be typical of such habitats (Mortelmans J. \& Van de Meutter F., pers. obs., Szadziewski, 1983). It appears that PBM communities differ greatly from their tidal counterparts by having much richer sciomyzid communities.

Malaise traps proved to be a reliable method for sampling snail-killing flies. Standard Malaise traps intercept insects flying less than a meter above the soil. Because of their intimate link to ground-dwelling slugs and snails, snailkilling flies are mostly found close to the ground (Knutson \& Vala, 2011; Murphy et al., 2012) and therefore are well sampled by Malaise traps. Whether Malaise traps provide unbiased community samples is another issue and is challenged by Carey et al. (2015), however their study is based on a very small sample compared to ours. How strong any sampling bias may be for sciomyzid flies remains to be established. More importantly, our results indicate that Malaise traps placed within the same marshland (but still 50-500 m distant) yielded very comparable results (Figs 2, 3 ). This is also reported by Carey et al. (2017) who associated it with the restricted mobility of snail-killing flies and their strong affinity for specific, local conditions (Williams et al., 2010). This is an important finding, as it gives further support both for our method of sampling marshland sciomyzid fauna and the results obtained.

Polder brackish marshland conservation and management is mainly focused on birds and vegetation. Continuing threats to the persistence of ancient PBMs and the strong management focus on birds highlights the need for more knowledge on other aspects of the biodiversity in these habitats. Previous research show the high intrinsic value of Belgian PBMs for horse-flies (Tabanidae) and their dependence on a stable groundwater level (Van de Meutter et al., 2016a). Current study shows that PBM may house moderately diverse communities of snail-killing flies, however they are not as important a sciomyzidae habitat as inland freshwater marshes. Species diversity, species density and abundance were higher in the less saline PBMs, which indicates that the importance of PBM for snail-killing flies increases with decreasing salinity. With respect to the sampling technique, our study revealed that Malaise traps provide highly repeatable and site-specific results and are very suitable for the study of snail-killing fly communities. We conclude that PBMs in Belgium are not inhabited by abundant or specific sciomyzid flies, but that their importance increases with decreasing soil salinity.

ACKNOWLEDGEMENTS. We are grateful to the following people and organizations for granting us access to their properties and/or helping with servicing and sorting the Malaise traps: Belgian defence, J. Van Gompel, Natuurpunt VZW, M. Pollet, S.
Pierret, R. Uyttenbroeck, R. Baets, S. Loose, P. D'hoore and M. Froidmont.

\section{REFERENCES}

Airoldi L. \& BECK M.W. 2007: Loss, status and trends for coastal marine habitats of Europe. - Oceanogr. Mar. Biol. Annu. Rev. 45: 345-405.

BAKKER J.P. 2014: Ecology of Salt Marshes. 40 Years of Research in the Wadden Sea. Wadden Academy, Leeuwarden, 53 pp.

Bakker J.P., Remans K., BeKker R.M., Steendam H., van Gompel J. \& Hermy M. 2009: Herstel van zilte graslanden in Vlaamse kustpolders. — Levende Nat. 110: 220-224.

Beintema A.J. \& Timmerman A. 1976: De Tureluur als "zoutliefhebber." — Het Vogeljaar 24: 17-21.

Carey J.G.J., Leroy M., Williams C.D. \& Gormally M.J. 2015: Observations concerning the sampling of Sciomyzidae (Diptera) in high nature value wet grassland habitats: Caveats to consider. — Insect Conserv. Divers. 8: 573-577.

Carey J.G.J., Brien S., Williams C.D. \& Gormally M.J. 2017: Indicators of Diptera diversity in wet grassland habitats are influenced by environmental variability, scale of observation, and habitat type. - Ecol. Indic. 82: 495-504.

Chapman E.G., Foote B.A., Malukiewicz J. \& Hoeh W.R. 2006: Parallel evolution of larval morphology and habitat in the snailkilling fly genus Tetanocera. — J. Evol. Biol. 19: 1459-1474.

Costil K., Dussart G.B.J. \& Daguzan J. 2001: Parameters structuring populations of aquatic gastropods in the region of Mont Saint-Michel (France). - Biodiv. Conserv. 10: 1-18.

De Caceres M. \& Legendre P. 2009: Associations between species and groups of sites: indices and statistical inference. Ecology 90: 3566-3574.

Dufrêne M. \& LEGENDRE P. 1997: Species assemblages and indicator species : The need for a flexible asymmetrical approach. - Ecol. Monogr. 67: 345-366.

Feys S., JAcobs I. \& De SAeger S. 2015: Lokalisering van de zilte habitattypes in de regio polders in West-Vlaanderen en het Meetjesland. Rapporten van het Instituut voor Natuur- en Bosonderzoek, Brussel, 31 pp.

Gedan K.B., Silliman B.R. \& Bertness M.D. 2008: Centuries of human-driven change in salt marsh ecosystems. - Annu. Rev. Mar. Sci. 1: 117-141.

Gérard C., Blanc A. \& Costil K. 2003: Potamopyrgus antipodarum (Mollusca: Hydrobiidae) in continental aquatic gastropod communities: impact of salinity and trematode parasitism. - Hydrobiologia 493: 167-172.

Gotelli J.N. \& Colwell R.K. 2001: Quantifying biodiversity: procedures and pitfalls in the measurement and comparison of species richness. - Ecol. Lett. 4: 379-391.

Janssen J.A.M., Rodwell J.S., Criado M.G., Gubbay S.T., Haynes A.N., Sanders N., Landucci F., Loidi J., Ssymank A., TAhVAnainen T. ET AL. 2017: European Red List of Habitats. Part 2. Terrestrial and Freshwater Habitats. Publications Office of the European Union, Luxembourg, $44 \mathrm{pp}$.

Keiper J.B., Walton W.E. \& Foote B.A. 2002: Biology and Ecology of the higher Diptera from freshwater wetlands. - Annu. Rev. Entomol. 47: 207-232.

Knutson L.V. \& VAla J.-C. 2011: Biology of Snail-Killing Sciomyzidae Flies. Cambridge University Press, Cambridge, 506 pp.

McCune B. \& Mefford M.J. 2016: PC-ORD. Multivariate Analysis of Ecological Data. Ver. 7. MjM Software Design, Gleneden Beach, Oregon, U.S.A.

Millennium Ecosystem Assessment 2005: Ecosystems and Human Well-Being: Synthesis. The Millennium Ecosystem 
Assessment Series. URL: http://catdir.loc.gov/catdir/toc/ ecip062/2005029022.html.

Murphy W.L., Knutson L.V., Chapman E.G., Mc Donnell R.J., Williams C.D., Foote B.A. \& Vala J.-C. 2012: Key aspects of the biology of snail-killing Sciomyzidae flies. - Annu. Rev. Entomol. 57: 425-447.

NefF S. \& Berg C. 1962: Biology and immature stages of Hoplodictya spinicornis and H. setosa (Diptera: Sciomyzidae). Trans. Am. Entomol. Soc. 88: 77-93.

Oksanen J., Blanchet F.G., Friendly M., Kindt R., Legendre P., McGlinn D., Minchin P.R., O’Hara R.B., Simpson G.L., SolyMOS P. ET AL. 2018: vegan: Community Ecology Package. $R$ Package Ver. 2.5-2.

Pennings S.C. 2012: The big picture of marsh loss. - Nature 490: $352-353$.

RozkošNÝ R. 1984: The Sciomyzidae (Diptera) of Fennoscandia and Denmark. Fauna Entomol. Scand. 14. Scandinavin Science Press, Leiden and Copenhagen, 224 pp.

RozkošnÝ R. 1991: A key to the Palaearctic species of Pherbellia Robineau Desvoidy, with descriptions of three new species (Diptera, Sciomyzidae). — Acta Soc. Zool. Bohem. 88: 391406.

RStudio Team 2016: RStudio: Integrated Development for $R$. RStudio, Boston, MA, URL: http://www.rstudio.com.

SzADZIEWSKI R. 1983: Flies (Diptera) in the saline habitats of Poland. - Bull. Entomol. Pologne 53: 31-76.

Vala J.C. 1989: Diptères Sciomyzidae Euro-méditerranéens. Faune de France. France et Régions Limitrophes. No. 72. Fédération Française des Sociétés de Sciences Naturelles, Paris, $300 \mathrm{pp}$.
Vala J.-C., Murphy W.L., Knutson L.V. \& RozkoŠnÝ R. 2012: A cornucopia for Sciomyzidae (Diptera). — Stud. Dipterol. 19: 67-137.

Van de Meutter F., Gyselings R. \& Van den Bergh E. 2016a: The occurrence and ecological requirements of the horse-flies (Tabanidae) of brackish marshes in Belgium. - J. Insect Conserv. 20: 989-997.

Van de Meutter F., Gyselings R. \& Van den Bergh E. 2016b: Onderzoek naar de inrichting van binnendijkse zilte graslanden. Instituut voor Natuur- en Onderzoek, Brussel, 168 pp.

Wieski K., Guo H., Craft C.B. \& Pennings S.C. 2010: Ecosystem functions of tidal fresh, brackish and salt marshes on the Georgia coast. - Estuar. Coasts 33: 161-169.

Williams C.D., Moran J., Doherty O., Mc Donnell R.J., GorMALly M.J., KNUTSON L.V. \& VALA J.C. 2009: Factors affecting Sciomyzidae (Diptera) across a transect at Skealoghan Turlough (Co. Mayo, Ireland). - Aquat. Ecol. 43: 117-133.

Williams C.D., Gormally M.J. \& KNutson L.V. 2010: Very high population estimates and limited movement of snail-killing flies (Diptera: Sciomyzidae) on an Irish turlough (Temporary Lake). - J. Environ. Biol. 110: 81-94.

Wolters M., Garbutt A. \& Bakker J.P. 2005: Salt-marsh restoration: evaluating the success of de-embankments in northwest Europe. - Biol. Conserv. 123: 249-268.

Zwaenepoel A., T'Jollyn F., Vandenbussche V. \& Hoffmann M. 2002: Systematiek van natuurtypen voor Vlaanderen: 6.1 Graslanden partim Zilte en storingsgraslanden. Ministerie van de Vlaamse Gemeenschap, Brussel, 55 pp.

Received January 11, 2020; revised and accepted April 9, 2020 Published online June 16, 2020 